\title{
OAREL

\section{Developing Battery Computer Aided Engineering Tools for Military Vehicles}

Prepared by

Ahmad Pesaran, Project Lead

Chuanbo Yang

Shriram Santhanagopalan

Gi-Heon Kim

Kandler Smith

National Renewable Energy Laboratory

Golden, Colorado

Andreas Vlahinos

Advanced Engineering Solutions

Castle Rock, Colorado

Prepared for U.S. Army TARDEC Under Army-DOE Interagency Agreement IAG 12-1855

NREL is a national laboratory of the U.S. Department of Energy Office of Energy Efficiency \& Renewable Energy

Operated by the Alliance for Sustainable Energy, LLC

December 2013 


\section{Report Documentation Page}

Public reporting burden for the collection of information is estimated to average 1 hour per response, including the time for reviewing instructions, searching existing data sources, gathering and maintaining the data needed, and completing and reviewing the collection of information. Send comments regarding this burden estimate or any other aspect of this collection of information, including suggestions for reducing this burden, to Washington Headquarters Services, Directorate for Information Operations and Reports, 1215 Jefferson Davis Highway, Suite 1204, Arlington VA 22202-4302. Respondents should be aware that notwithstanding any other provision of law, no person shall be subject to a penalty for failing to comply with a collection of information if it does not display a currently valid OMB control number.

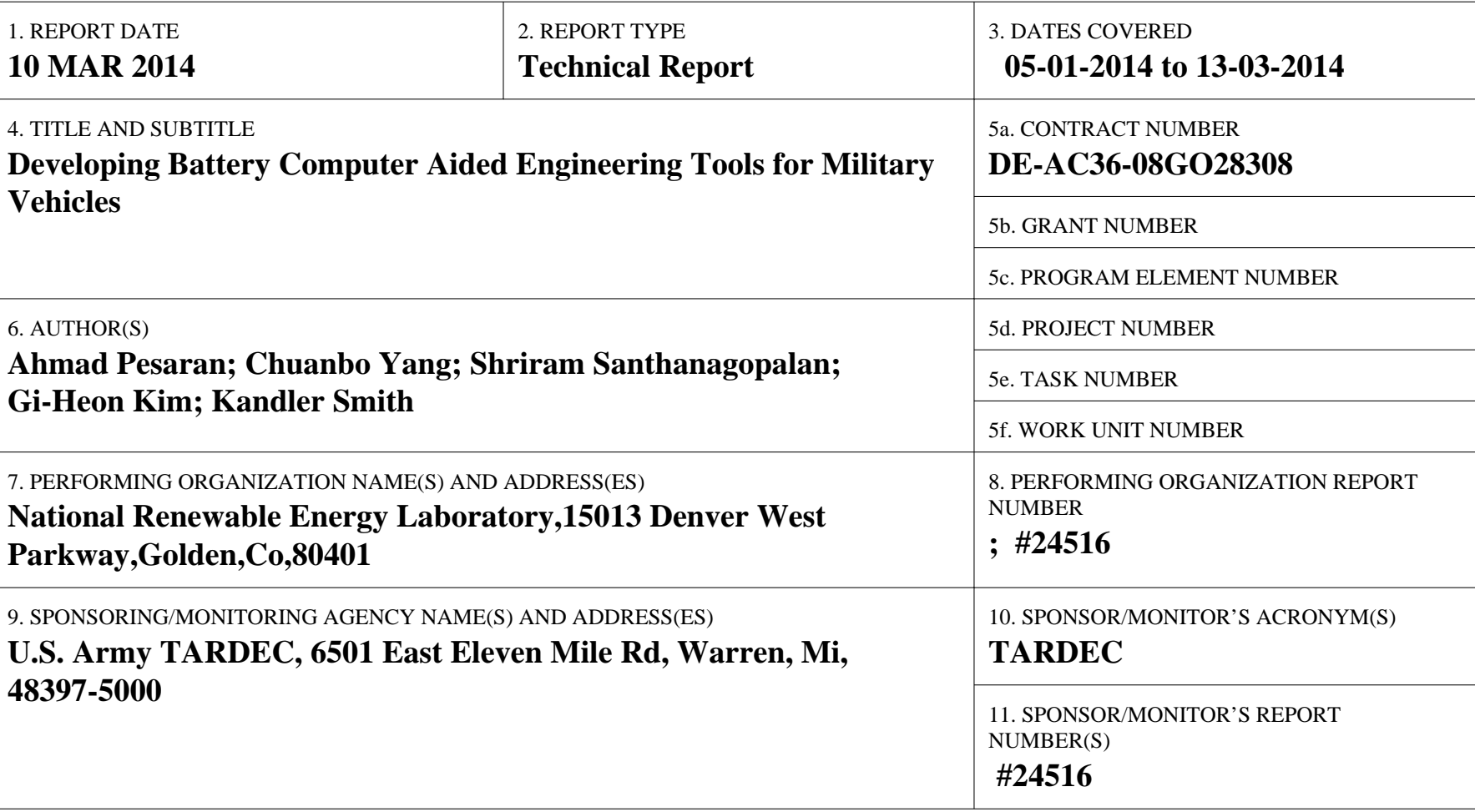

12. DISTRIBUTION/AVAILABILITY STATEMENT

Approved for public release; distribution unlimited

13. SUPPLEMENTARY NOTES

Prepared for U.S. Army TARDEC Under Army-DOE Interagency Agreement IAG 12-1855

14. ABSTRACT

In July 2011, the Advanced Vehicle Power and Technology (AVPT) Alliance was announced as a partnership between the U.S. Department of Energy (DOE) and the U.S. Department of Army (DA) to explore solutions for decreasing petroleum dependence, increasing fuel efficiency and enhancing the nation's energy security infrastructure. The AVPT Alliance examines areas of interest that could serve as common ground for collaboration between DA and DOE, including: advanced combustion engines, lightweight materials, energy recovery, alternative fuels, analytical tools, and hybrid propulsion systems including batteries. The Army's Tank Automotive Research, Development and Engineering Center (TARDEC) and DOE's Vehicle Technologies Office (VTO) are collaborating as part of this partnership. VTO has been supporting development of software design tools for accelerating development of batteries for electric drive vehicles for civilian applications under the Computer Aided Engineering of Batteries (CAEBAT) project. Extending the CAEBAT tools for vehicles in military applications was chosen as one the areas for collaboration between VTO and TARDEC under the AVPT partnership.

15. SUBJECT TERMS

16. SECURITY CLASSIFICATION OF:

a. REPORT

unclassified b. ABSTRACT unclassified c. THIS PAGE unclassified
17. LIMITATION OF ABSTRACT

Public

Release
18. NUMBER OF PAGES 32 19a. NAME OF RESPONSIBLE PERSON 
Standard Form 298 (Rev. 8-98) Prescribed by ANSI Std Z39-18 
Developing Battery Computer Aided Engineering Tools for Military Vehicles

Prepared by

Ahmad Pesaran, Project Lead

C. Yang

S. Santhanagopalan

G.H. Kim

K. Smith

National Renewable Energy Laboratory

Golden, Colorado

A. Vlahinos

Advanced Engineering Solutions

Castle Rock, Colorado

NREL is a national laboratory of the U.S. Department of Energy Office of Energy Efficiency \& Renewable Energy

Operated by the Alliance for Sustainable Energy, LLC 


\section{NOTICE}

This report was prepared as an account of work sponsored by an agency of the United States government. Neither the United States government nor any agency thereof, nor any of their employees, makes any warranty, express or implied, or assumes any legal liability or responsibility for the accuracy, completeness, or usefulness of any information, apparatus, product, or process disclosed, or represents that its use would not infringe privately owned rights. Reference herein to any specific commercial product, process, or service by trade name, trademark, manufacturer, or otherwise does not necessarily constitute or imply its endorsement, recommendation, or favoring by the United States government or any agency thereof. The views and opinions of authors expressed herein do not necessarily state or reflect those of the United States government or any agency thereof. 


\title{
Foreword
}

The U.S. Army's Tank Automotive Research, Development and Engineering Center (TARDEC) funded the U.S. Department of Energy's (DOE's) National Renewable Energy Laboratory (NREL) to extend the Computer-Aided Engineering for Automotive Batteries (CAEBAT) tools for batteries used in military applications. This was in support of a larger partnership between the U.S. Army and DOE called the Advanced Vehicle Power and Technology Alliance. NREL is the lead laboratory for coordinating CAEBAT projects for DOE's Vehicle Technologies Office.

The ultimate goal of TARDEC was to further enhance physics-based simulation tools developed by DOE to predict battery response to accelerate fielding optimized batteries in electrified military vehicles. Particularly, TARDEC's objective was the development of tools to accelerate comparative analysis of alternative lithium-ion batteries designed as drop-in replacements for existing lead-acid cells in 6T battery modules. In support of TARDEC, NREL's objective was to modify and extend DOE-CAEBAT battery simulation tools to predict the response of lithium-ion battery modules under situations experienced in military applications, including hot environments, bullet penetration, and mechanical stress. NREL's eventual goal is to develop tools and procedures so TARDEC staff can accelerate fielding safe, high-performance, and long-lasting lithium-ion batteries in electrified vehicles for military applications.

This project was executed under U.S. Army-DOE Interagency Agreement IAG 12-1855, which began in June 2012, and was completed in December 2013. The Energy Storage Group of NREL's Transportation and Hydrogen Systems Center performed the work to complete the project, with support from subcontract agreements with Advanced Engineering Solutions, the University of Colorado at Boulder, and the Lockheed Martin Corporation (thanks to Jeremy Neubauer of NREL for overseeing this subcontract).

We appreciate the funding granted by TARDEC, and support provided by Yi Ding and Sonya Zanardelli. We also appreciate the support of Brian Cunningham and David Howell of the DOE Vehicle Technologies Office by engaging NREL in the Army-DOE collaboration.

\author{
Ahmad Pesaran, Ph.D. \\ Project Lead \\ Energy Storage Group Manager \\ Transportation and Hydrogen Systems Center \\ National Renewable Energy Laboratory \\ Golden, Colorado \\ 303-275-4441 \\ ahmad.pesaran@nrel.gov
}




\section{Outline}

\section{Executive Summary}

1. Safety and Abuse Modeling of Cells

a. Thermal runaway due to heating

b. Bullet threat/strike/penetration

i. Modeling using multi-layer puncture approach

ii. Modeling using dynamic structural analysis tools

iii. Bullet penetration testing for "validation"

2. Multi-scale Electrochemical Modeling with Mechanical Degradation

a. Stress in electrodes

3. Interactions with TARDEC End Users

Proposed Future Work 


\section{Executive Summary}

Context: In July 2011, the Advanced Vehicle Power and Technology (AVPT) Alliance was announced as a partnership between the U.S. Department of Energy (DOE) and the U.S. Department of Army (DA) to explore solutions for decreasing petroleum dependence, increasing fuel efficiency and enhancing the nation's energy security infrastructure. The AVPT Alliance examines areas of interest that could serve as common ground for collaboration between DA and DOE, including: advanced combustion engines, lightweight materials, energy recovery, alternative fuels, analytical tools, and hybrid propulsion systems including batteries. The Army's Tank Automotive Research, Development and Engineering Center (TARDEC) and DOE's Vehicle Technologies Office (VTO) are collaborating as part of this partnership. VTO has been supporting development of software design tools for accelerating development of batteries for electric drive vehicles for civilian applications under the Computer Aided Engineering of Batteries (CAEBAT) project. Extending the CAEBAT tools for vehicles in military applications was chosen as one the areas for collaboration between VTO and TARDEC under the AVPT partnership.

Project: Based on the recommendations from VTO, TARDEC decided to extend CAEBAT tools for military applications by working with DOE's National Renewable Energy Laboratory (NREL), the lead national laboratory for coordinating CAEBAT. TARDEC provided funding to NREL in June 2012 with the ultimate goal of further enhancing physics-based simulation tools developed by DOE to predict battery response to accelerate fielding optimized batteries in electrified military vehicles. Particularly, TARDEC's objective was the development of tools to accelerate comparative analysis of alternative lithium-ion battery designs as drop-in replacements for existing lead-acid cells in $6 \mathrm{~T}$ battery modules. In support of TARDEC, NREL's objective was to modify and extend the DOE-CAEBAT battery simulation tools to predict the response of lithiumion battery modules under abuse conditions experienced in military applications (including hot environments and bullet penetration) and mechanical stress.

Tasks Description: The project was divided into two major tasks: 1) Safety and Abuse Modeling of Cells and 2) Multi-scale Electrochemical Modeling with Mechanical Degradation. Task 3 was added for Interactions with TARDEC End Users. Task 1 was further divided into two subtasks: Task 1.a Modeling Thermal runaway due to heating and Task 1.b Modeling Bullet penetration. The purpose of Task 1.a was to extend the chemical kinetics models of $\mathrm{CoO}_{2}$ cathodes developed under CAEBAT to other chemistries using a differential scanning calorimeter and an accelerating rate calorimeter. The purpose of Task 1.b was to simulate the physics of bullet penetration into a battery cell. Simulating all of the physics of a bullet penetrating into a cell or battery, and subsequent mechanical damage and potential thermal runaway resulting from short circuit heat release, is very complex. Because of this complexity, Task 1.b examined two approaches for modeling. Two subtasks were created: Task 1.b.i, Multi-layer Puncture Model, and Task 1.b.ii, Mechanical Crush Model. Task 1.b.i assumed that bullet penetration resulted in the puncture of electrode layers, creating statistically-identical short-circuited layers that could be modeled 
electrochemically-thermally; an NREL CAEBAT model was extended for this subtask. Task 1.b.ii captured the physical state of a cell after bullet penetration using mechanical crush models and then predicting the thermal response using the dynamic modeling commercial software LS_DYNA; bullet penetration data for validation was obtained through field tests performed by Lockheed Martin in Littleton, Colorado, for this subtask. After initial investigations for Task 2 to include stress in life modeling, it was determined that it would be more effective to collaborate with experts at the University of Colorado at Boulder to include electrode mechanical stress in NREL's multi-scale electrochemical-thermal model to investigate the magnitude of stress factors on the degradation and loss of capacity in cells. For Task 3, quarterly progress review meetings were held with TARDEC staff to discuss project results and approaches to determine how the models would be most useful to end users.

Task Summaries: Summary of the work performed for each task

Task 1.a. Safety and Abuse Modeling of Cells - Thermal runaway due to heating

A MATLAB script to generate kinetic parameters for the abuse reactions from experimental DSC/ARC data was developed. This model can be used by the end-user in combination with experimental data for a variety of chemistries to regress the activation energies, rate-constants, and orders of reaction among individual cell components. Experimental data for the different reactions pertaining to the NMC chemistry were generated. Results from this task will serve as input to computational fluid dynamic simulations in calculating the self-heating rate for the different abuse reactions.

\section{Task 1.b.i. Bullet Penetration - Modeling using Multi-layer Puncture Approach}

NREL researchers developed the multi-layer puncture response model to provide a physicsbased, flexible, and efficient simulation methodology to predict electrical-thermal-chemical responses of battery cells/packs subject to sudden mechanical failures, such as crush or penetration. A co-simulation environment, linking NREL's electrochemical, electro-thermal and abuse reaction kinetics models, has been established to simulate battery responses to mechanical abuse. We demonstrated the model capability, applicable to various form factor cells (e.g. pouch, cylindrical, and wound prismatic cells), via three complementary approaches for electro-thermal modeling. The model validation was carried out against experimental data provided by NRL and SNL.

\section{Task 1.b.ii. Bullet Penetration - Modeling using Dynamic Structural Analysis Tools}

The main objective of this task was to evaluate and select finite element analysis (FEA) modeling techniques that can effectively simulate the physical state of batteries after bullet penetration. As part of the FEA modeling, we implemented alternate formulations to better understand what simplifications would be accurate to adopt. A parametric robust explicit dynamics FEA model in LS_DYNA was developed to predict bullet penetration geometry. We found that having appropriate material properties is critical for accurate prediction of model behavior. 


\section{Task 1.b.iii. Bullet Penetration - Testing for "Validation"}

In order to check the validity of these models, we tried to obtain data on the state of a cell after bullet penetration. Except for some limited data from an Army Research Lab (ARL) report on bullet strike with a lithium-ion pack containing cylindrical cells, we could not obtain any publicdomain bullet penetration test results for the cells in which TARDEC was interested. Lacking data meaningful to our efforts, we decided to perform bullet penetration tests under this task to gain more insight for "validation" of the models. To conduct these tests, we subcontracted Lockheed Martin Corporation (LMCO) in Littleton, Colorado. 25 Ah cylindrical cells from Saft and 20 Ah soft pouch prismatic cells from A123 Systems were tested. LMCO performed bullet tests with stringent safety procedures using a 0.308 -caliber NATO rifle and ammunition. Cells were tested at $0 \%, 50 \%$, and $100 \%$ SOC. Data were collected with high-speed instrumentation and videos. Most cells lost voltage after bullet penetration. Only the cells at $100 \%$ SOC showed signs of high temperatures or thermal runaway. Full 3D CT scans of the cylindrical cell at $100 \%$ SOC penetrated by a bullet at $90^{\circ}$ showed the shock wave from the bullet heavily damaged electrodes throughout the entire cell, and was not limited to the bullet penetration site. Generally, the pouch prismatic cells saw much less damage than the wound cylindrical cells, perhaps due to lack of destructive shock waves. The bullet penetration tests provided insight on how cells are impacted physically and potential subsequent thermal events depending on situational geometry, chemistry, SOC, and angle of attack. 3D CT scans provided insightful information to further understand what happened to the cells upon bullet impact. The number of tests performed was limited, due to budget constraints and availability of cells, but the tests provided useful information on improving bullet penetration models.

\section{Task 2. Multi-scale Electrochemical Modeling with Mechanical Degradation}

Batteries suffer from capacity and power fade due to mechanical-, thermal- and electrochemical-coupled physics. To date, no battery CAE model exists that is capable of predicting large-format cell lifetime and providing design feedback for 3D cell and module design. As an initial step towards filling this gap, NREL and the University of Colorado at Boulder developed and linked new solid mechanics models to explore mechanical phenomena in lithiumion batteries. The new finite element model captures swelling/shrinking in cathodes/anodes due to thermal expansion and lithium intercalation, as well as in-plane and out-of-plane deformation. Transport of lithium, transport of heat, and generation of heat are provided through linkage with NREL's pre-existing electrochemical-thermal Multi-Scale Multi-Domain (MSMD) model. Example simulations are run for an 8Ah Dow-Kokam pouch cell.

\section{Task 3. Interactions with TARDEC End Users}

The NREL project team held several web meetings and one face-to-face discussion with the TARDEC project team to learn about the eventual end use of project modeling tools in order to modify and adjust them to better meet TARDEC's needs. The NREL team learned about the $6 T$ module, the cells, and the chemistries that TARDEC was considering for drop-in replacements 
for lead-acid batteries. To make the models useful, we prepared instructions for their use to be shared with TARDEC.

\section{Proposed Future Work}

Future work includes implementing case studies of immediate interest to TARDEC. One example is the study of the response of cells in the $6 \mathrm{~T}$ module to abuse scenarios using the models described above. If TARDEC can provide NREL with a few representative modules, NREL will build relevant simulations and test-plans to respond to queries about which design changes are most relevant to improve safety of the module under a particular failure mode. If funding becomes available, we would like to further study the data and results of bullet penetration tests and investigate the CT scans further. Then we would like to perform a set of more comprehensive bullet penetration tests on cells and representative $6 \mathrm{~T}$ modules. Along with modeling, bullet penetration tests, and CT scans, we will be able to provide tools to TARDEC to evaluate alternative Li-Ion $6 \mathrm{~T}$ battery designs and provide guidance to vendors on improving the design of $6 \mathrm{~T}$ modules with better performance, safety, and life. For future work, we propose extending the safety and life models developed under this project, along with CAEBAT performance models, to $6 \mathrm{~T}$ modules to be able to evaluate alternative designs by vendors so $6 \mathrm{~T}$ batteries may be further improved. The eventual goal is to achieve the expected TARDEC performance, safety, and life for $6 \mathrm{~T}$ batteries. 


\title{
1. Safety and Abuse Modeling of Cells \\ a. Thermal runaway due to heating
}

\author{
Prepared by Chuanbo Yang and Shriram Santhanagopalan
}

\section{Background}

NREL's abuse reaction kinetics model is used to simulate battery pack or cell response to high temperatures due to electrical, mechanical, and thermal abuse [1]. This model, for the present application, is implemented in MATLAB. The output of the model, heat generated, can be used by the end user to serve as input to computational fluid dynamic simulations as an energy source term in the energy balance equations.

NREL's abuse reaction kinetics model is capable of predicting instant heat generation rates due to abuse chemical reactions of cell components. There are four exothermic component reactions included that play relatively important roles in thermal runaway (Table 1). The reaction rates are experimentally determined by and an accelerating rate calorimeter (ARC) and/or differential scanning calorimeter (DSC) tests. These tests are performed at the cell component level to obtain the self-heating curves that can be compared with suitable kinetic equations to extract the rate coefficients. The key objective of abuse reaction modeling is to regress these experimental self-heating curves to extract kinetics parameters. The main factors affecting reaction rates are assumed to be the temperature at which the reaction occurs and the concentration of the reactants as a function of the state of charge (SOC).

Table 1. Abuse reactions included in NREL's abuse reaction kinetics model

\begin{tabular}{|c|l|l|}
\hline Reaction \# & Reaction & Possible Onset Temperature $\left({ }^{\circ} \mathrm{C}\right)$ \\
\hline $\mathbf{1}$ & $\begin{array}{l}\text { Solid Electrolyte } \\
\text { Interphase (SEI) layer } \\
\text { decomposition }\end{array}$ & 80 \\
\hline $\mathbf{2}$ & Anode - electrolyte & 100 \\
\hline $\mathbf{3}$ & Cathode - electrolyte & 130 \\
\hline $\mathbf{4}$ & Electrolyte decomposition & 180 \\
\hline
\end{tabular}

In order to apply this model to a specific cell design, or to modify it for other chemistries, the end users only need to update the variable values in the file of "ARK_Param.inp". The notes behind every value in this file, which can be modified using a text editor, indicate the corresponding parameter to which it is assigned. 


\section{Kinetic Equations}

In general, the self-heating rates can be determined by:

$$
\begin{aligned}
& \frac{d T}{d t}=\frac{h d \alpha}{C d t} \\
& \frac{d \alpha}{d t}=k(T) f(\alpha)
\end{aligned}
$$

()

$\left\{f(\alpha)=\alpha^{m}\left(1-\alpha^{n}\right)(-\ln (1-\alpha))^{p}\right.$

For each reaction, the type of the function $f(\alpha)$ is different and the variable $\alpha$ is defined as shown in Table 2.

\begin{tabular}{|c|c|c|c|c|c|c|}
\hline \multirow{2}{*}{ Reaction \# } & \multicolumn{3}{|c|}{ Parameters } & \multirow{2}{*}{$f(\alpha)=$} & \multirow{2}{*}{$\alpha$ (dimensionless) } & \multirow{2}{*}{$\alpha$, range } \\
\hline & $\mathrm{m}$ & $n$ & $\mathbf{p}$ & & & \\
\hline 1 & 1 & 0 & 0 & $\alpha$ & $\begin{array}{c}\text { Fraction of Li in } \\
\text { metastable SEI species }\end{array}$ & $0.16 \rightarrow 0$ \\
\hline 2 & 1 & 0 & 0 & $\alpha \times \exp \left(-t_{\text {sei }} / t_{\text {sei,ref }}\right)$ & $\begin{array}{l}\text { Fraction of Li intercalated } \\
\text { in the carbon }\end{array}$ & $0.75 \rightarrow 0$ \\
\hline 3 & 1 & 1 & 0 & $\alpha(1-\alpha)$ & Conversion of reactants & $1 \rightarrow 0$ \\
\hline 4 & 1 & 0 & 0 & $\alpha$ & Conversion of reactants & $1 \rightarrow 0$ \\
\hline
\end{tabular}

Table 2. Suggested parameters and initial values [2-4]

\section{Importing Experimental Data}

The MATLAB script provided with this document has provisions to import the data set directly from the data files generated during the ARC experiments. Sample data sets are shown in Figures 1 to 3 .

\section{Normalization of Experimental Data-sets}

Data normalization is necessary since multiple data sets (with various initial temperatures) are employed to estimate kinetic parameters, and the data spans more than one order of magnitude. As such, the normalization factor is chosen to weigh the data appropriately. The goodness of fit that is produced by minimizing the weighted sum of squares of deviations must be judged subjectively. It is suggested that the good ness of fit may be regarded as satisfactory if the data points are distributed uniformly on either side of the fitted curve [5].

A number of weighting factors were tested out. The most suitable one for current application is the use of:

\section{$/(7)$}


where $^{-}$is the mean of experimental data set.

The comparison of parameters estimated by original experimental data sets and weighted data sets is shown in Table 3.

Table 3. Comparison of parameters estimated using normalized versus original data sets

\begin{tabular}{|c|c|c|c|}
\hline Data-set & $\begin{array}{l}\text { Minimization } \\
\text { Function Options }\end{array}$ & $\begin{array}{l}\text { Parameters } \\
(\text { Ea, } A, m, n, p)\end{array}$ & $\begin{array}{l}\text { 2-norm of the } \\
\text { Residual }\end{array}$ \\
\hline Original & \multirow{2}{*}{$\begin{array}{l}\text { ('TolX', 1e-25, } \\
\text { 'TolFun', 1e-25, } \\
\text { 'MaxFunEvals', } \\
\text { 800000, 'Maxlter', } \\
\text { 800000); }\end{array}$} & $\begin{array}{l}(1.3322,1.0333 \mathrm{E} 13,2.9 \mathrm{E}- \\
14,2.9889,1.2388)\end{array}$ & $1.9734 \mathrm{E} 3$ \\
\hline Normalized & & $\begin{array}{l}(1.4127 \mathrm{E} 5,1.9769 \mathrm{E} 13 \\
6.3 \mathrm{E}-11,2.0535,0.5136)\end{array}$ & 0.028 \\
\hline
\end{tabular}

\section{Parameter Estimation}

ARC testing data of LCO cathode with electrolyte (LiPF6 + EC/DEC) [1-3], used to develop this parameter estimation tool, is shown in Figure 4. These results show that the self-heating rate (SHR) is a function of the sample temperature.

This non-linear least squares problem is solved in MATLAB using 'Isqcurvefit' function, one of the standard MATLAB subroutines within the optimization toolbox. Figure 5 illustrates the capability of this routine to find desired coefficient to best fit the SHR versus T curves.

As mentioned before, it is necessary to normalize the data first if its range is over one order of magnitude. Figures 6 and 7 show the fitting results with normalized and non-normalized data sets. The detailed setup and results are listed in Table 3 . The normalized data sets provide more accurate results. Figure 8 illustrates the fit based on two data sets, whose range is less than that of five data sets. Under such limited conditions, the need to scale the data set has limited implications, and the fit to the raw data provides acceptable results. The fitting results from the complete data set are plotted in Figures 9 and 10. It is assumed that a constant set of parameters (Table 3 ) is good for SHR prediction for cases with various initial temperatures. With the introduction of the data normalization scheme described above, each data set makes an equal contribution towards estimating the model parameters.

In order to generate the results shown in the following figures, the user must follow the sequence below:

a. Select the appropriate data set on the MATLAB file "load_dataset.m"

b. Make changes to the initial values from Tables 2 and 3 in the file "main.m" as required

c. Run the MATLAB file "main.m"

Note that the Optimization toolbox from MATLAB is necessary to use the Isqcurvefit function. 


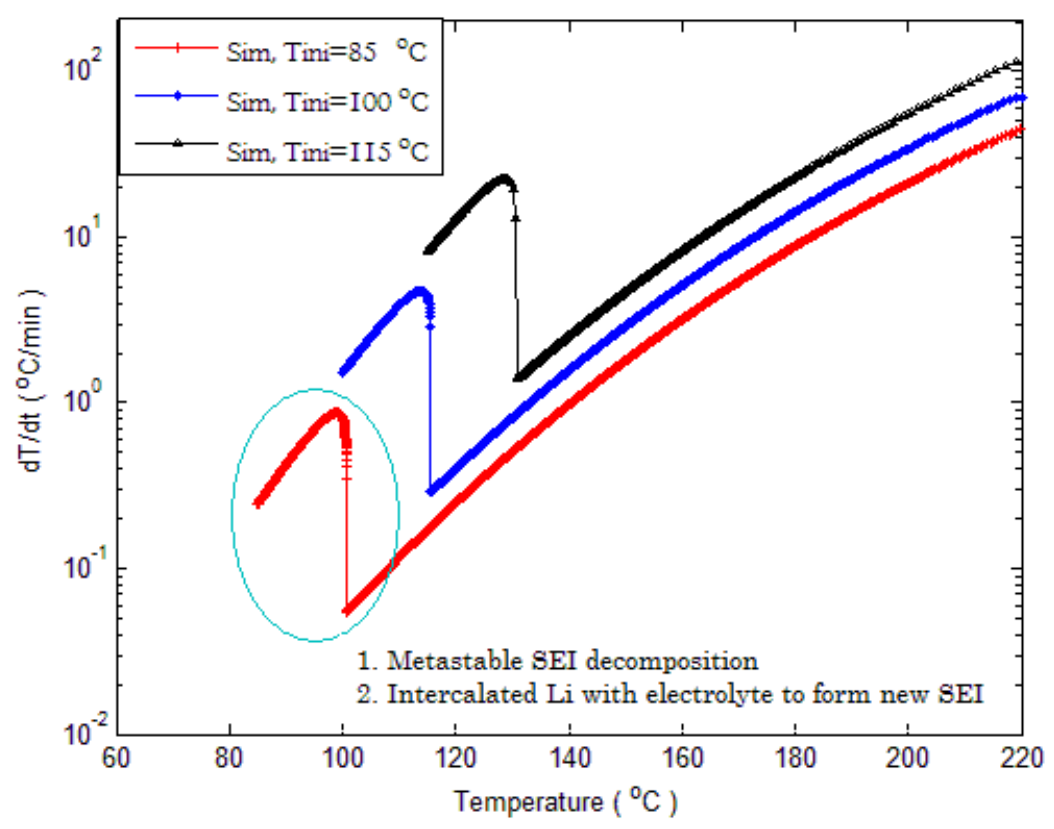

Figure 1. Self heating due to the reaction between anode and electrolyte



Figure 2. Self heating caused by the reaction between LCO cathode and electrolyte 


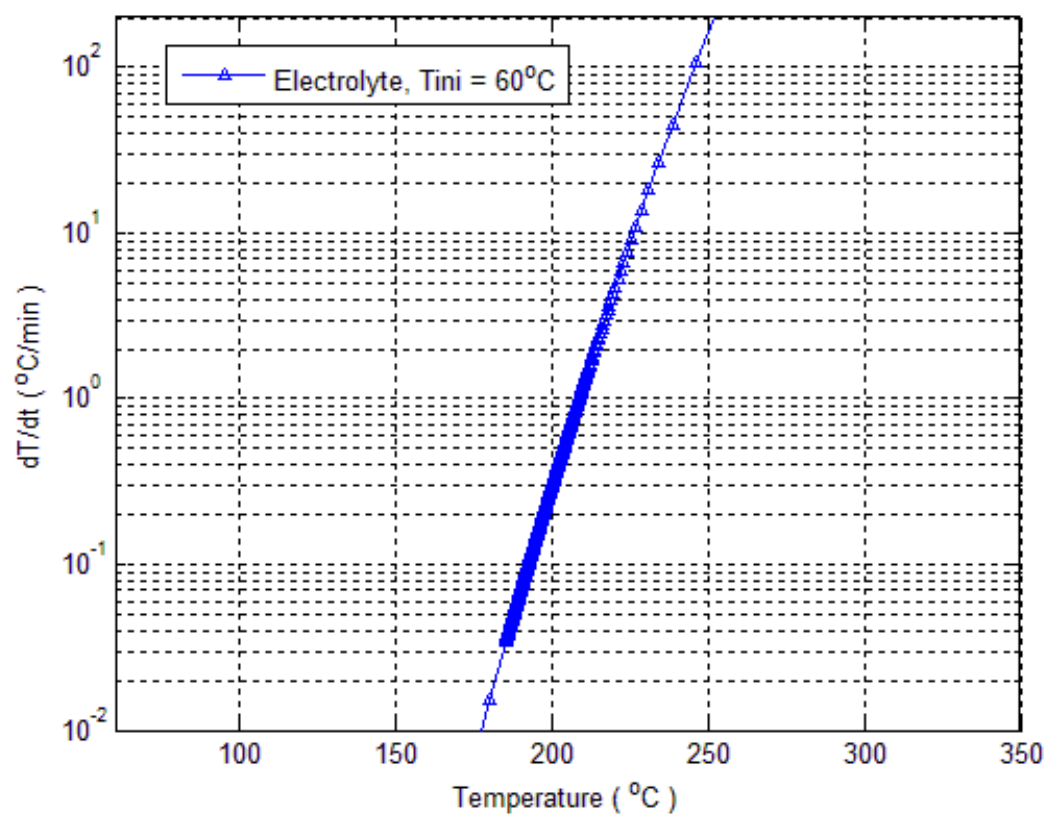

Figure 3. Self-heating-rate of the electrolyte decomposition reaction

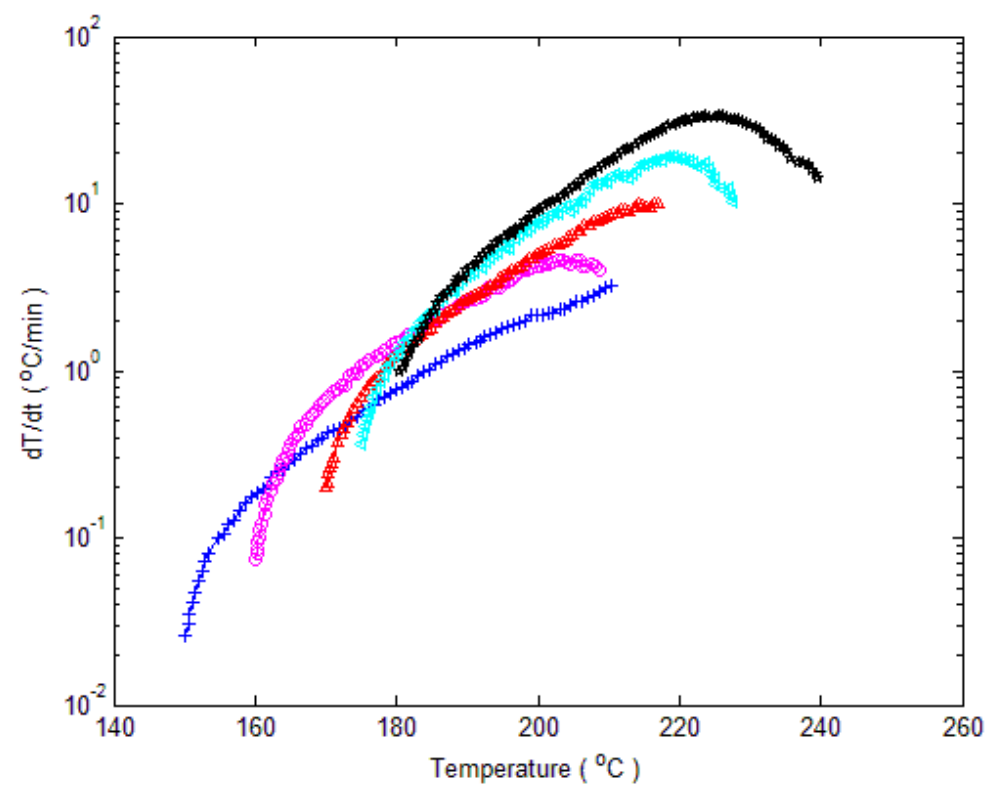

Figure 4. Experimental data sets used for estimating parameters of cathode-electrolyte reactions. Each color represents a different initial sample temperature for the onset of the abuse reaction 


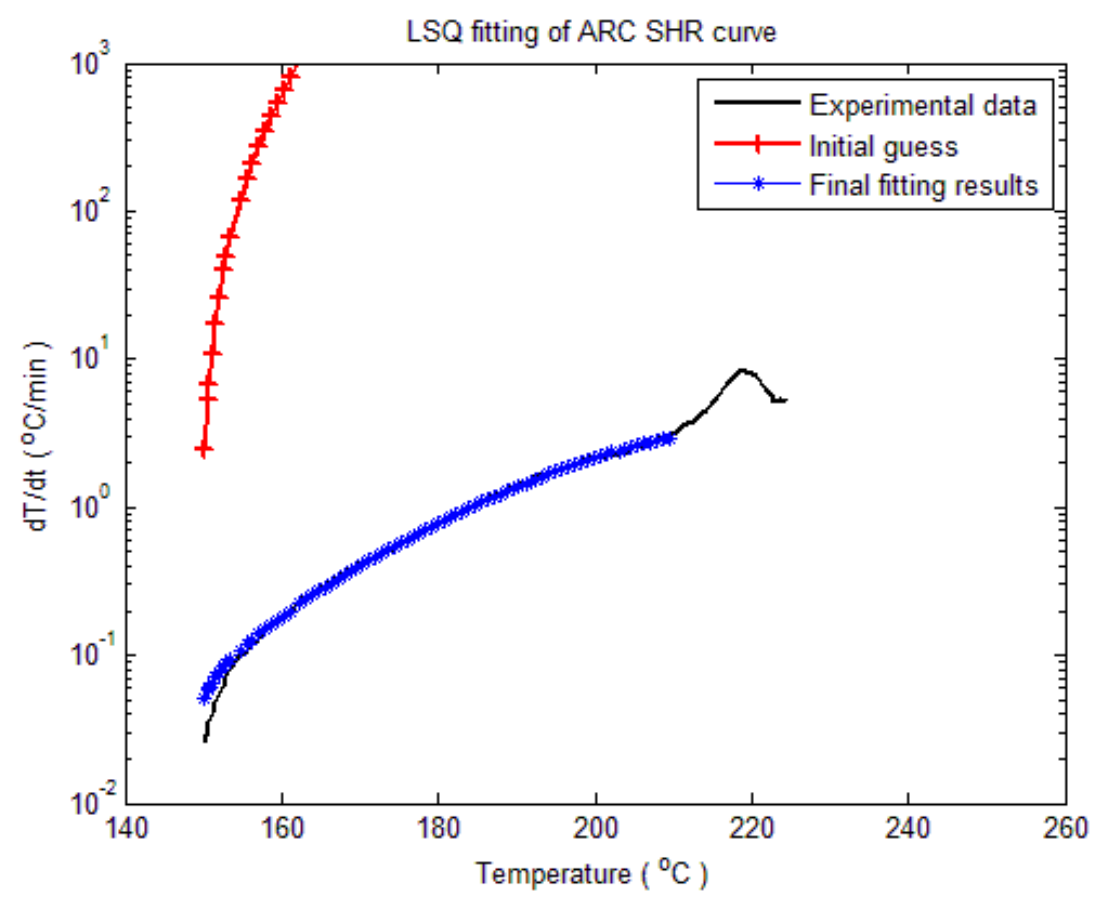

Figure 5. Comparison between initial guess and final fitting results

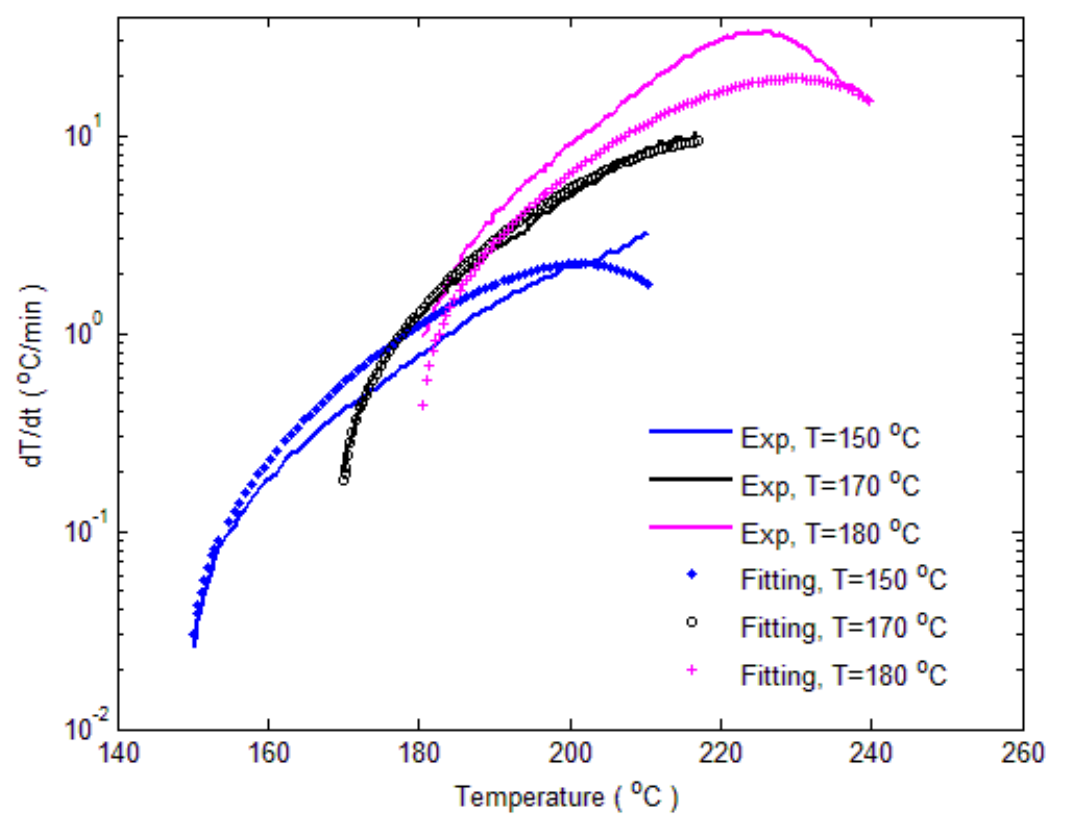

Figure 6. Fitting results using normalized data sets 


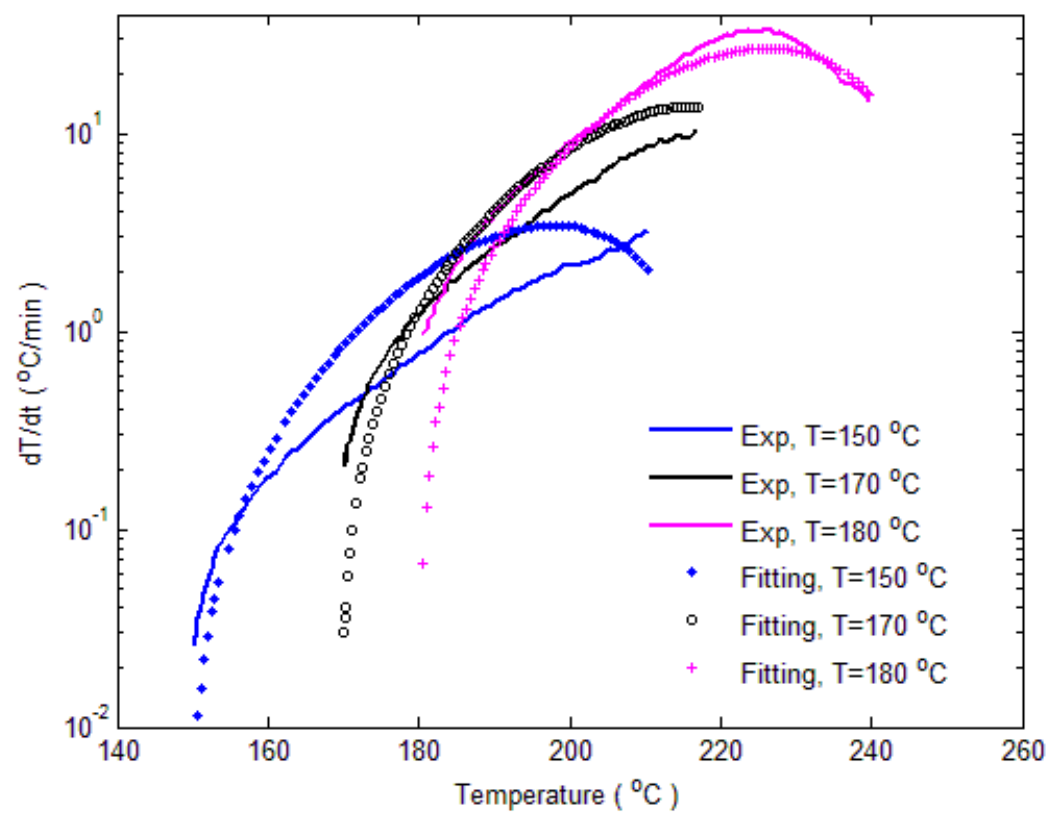

Figure 7. Fitting results based on non-normalized data sets
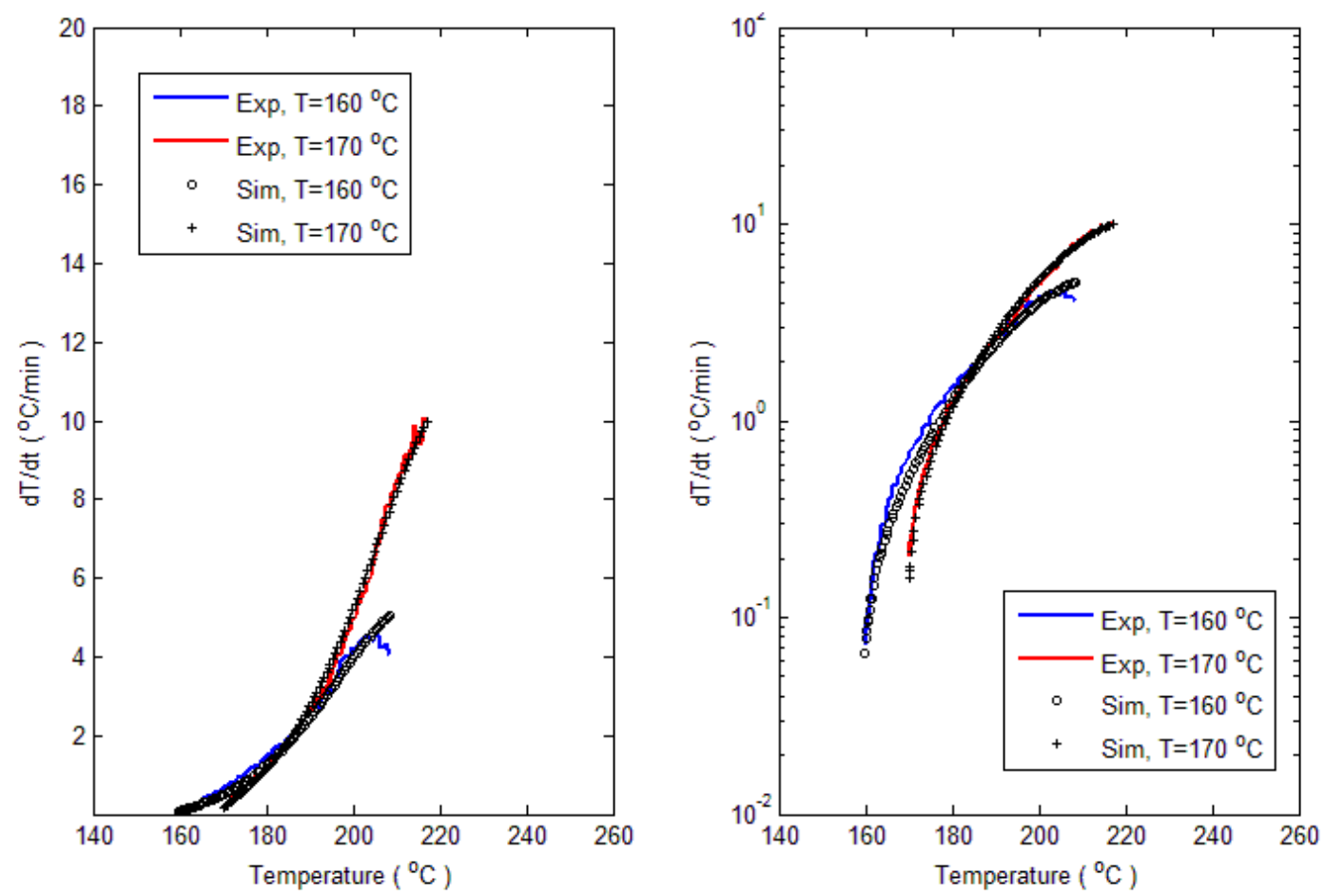

Figure 8. Fitting results based on non-normalized data sets: A subset of only two experimental conditions is shown 


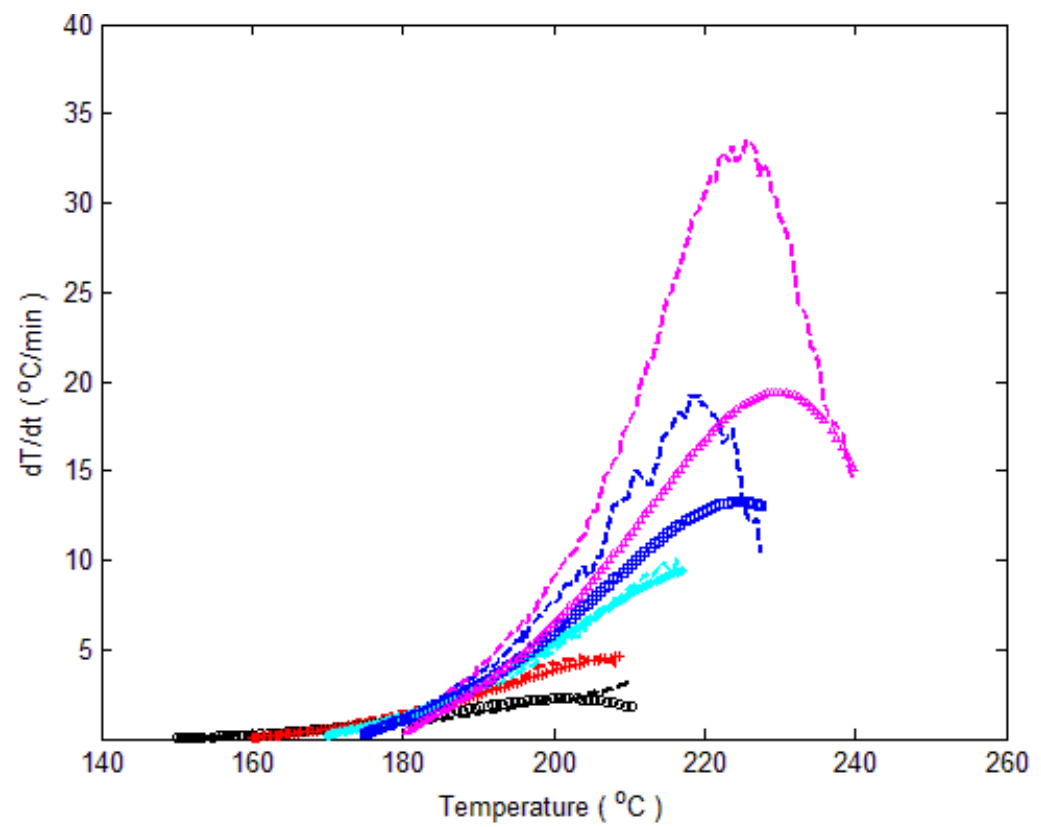

Figure 9. Fitting results based on the normalized data sets. Each color represents a different initial sample temperature for the onset of the abuse reaction. The lines represent the model estimates corresponding to the experimental data for each condition represented by symbols of the same color.

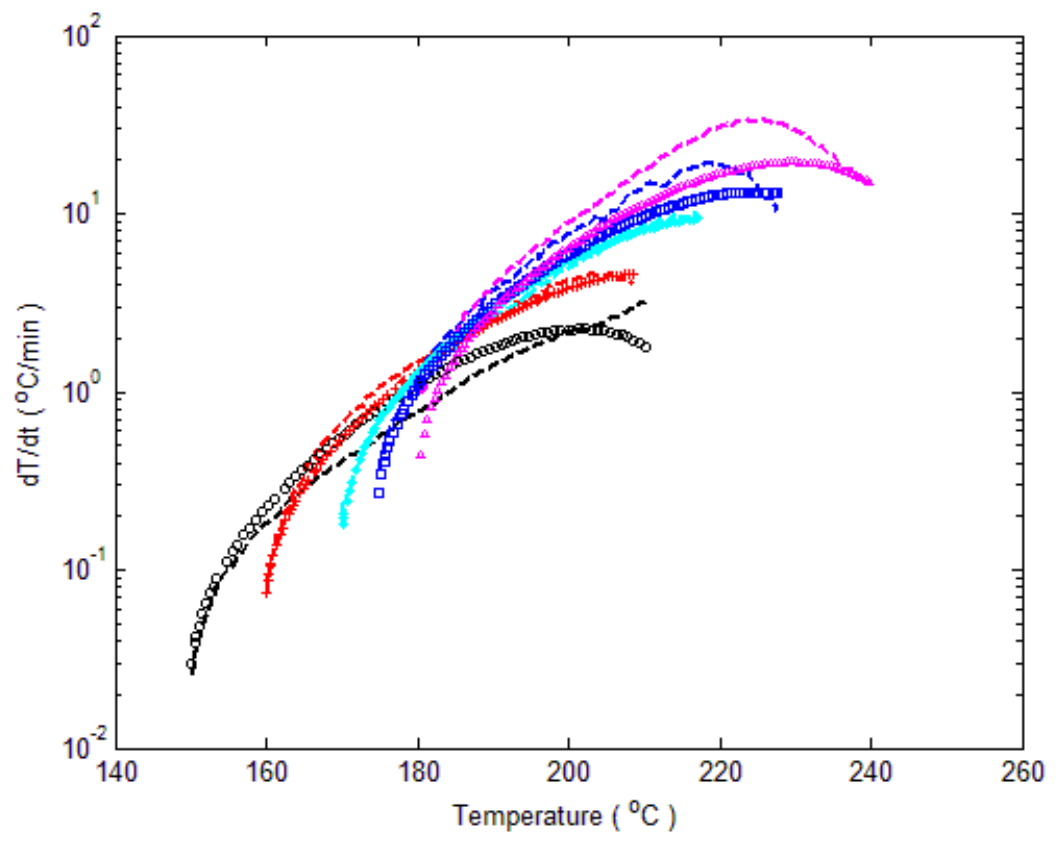

Figure 10. Fitting results based on the normalized data sets ( $Y$-axis is logarithmically scaled): each color represents a different initial sample temperature for the onset of the abuse reaction. The lines represent the model estimates corresponding to the experimental data for each condition represented by symbols of the same color. 
In summary, a flexible abuse-reaction model was developed that is chemistry-agnostic and userfriendly. The model can be customized to evaluate different chemistries of interest to TARDEC under the $6 \mathrm{~T}$ module evaluation project. The results from the MATLAB-based parameter estimation routine supplied with this report can be readily integrated with CFD simulations from NREL, or other third party software, under this or future programs at TARDEC. Future work will involve characterizing the iron-phosphate and NCA-based cells used by different vendors for the 6T module design. If TARDEC can supply NREL with cell components for these chemistries, we will include ARC-calibration and extraction of abuse-kinetics parameters specific to the celldesigns of interest to TARDEC. Comparison of cell performance due to increased impedance at cold temperatures and impact of ambient temperature on the rate of lithium plating are a few examples of reactions that will be tracked. These test results, performed both at the electrode and cell levels, will be used to provide design guidance to vendors, to address cold temperature issues.

\section{References}

[1] G-H. Kim, A. Pesaran, and R. Spotnitz, "A Three-Dimensional Thermal Abuse Model for Lithium-Ion Cells", Journal of Power Sources 170 (2007) 476-489

[2] D.D. MacNeil, D. Larcher, and J.R. Dahn, "Comparisin of the Reactivity of Various Carbon Electrode Materials with Electrolyte at Evaluated Temperature, J. Electrochem. Soc. 146(10)(1999) 3596-3602

[3] M.N.Richard, and J.R. Dahn, Accelerating Rate Calorimetry Study on the Thermal Stability of Lithium Intercalated Graphite in Electrolyte, J. Electrochem. Soc. 146(6)(1999) 2068-2077

[4] D.D.MacNeil, et al., An Autocatalytic Mechanism for the Reaction of LixCoO2 in Electrolyte at Evaluated Temperature, J. Electrochem. Soc. 147(3)(2000) 970-979

[5] J.H. Ottaway, Normalization in the Fitting of Data by Iterative Methods. Application to tracer kinetics and enzyme kinetics. Biochem J. 1973 Jul; 134(3):729-736



Please click above to link to the presentation 


\title{
1. Safety and Abuse Modeling of Cells \\ b. Bullet threat/strike/penetration \\ i. Modeling using multi-layer puncture approach
}

\author{
Prepared by Chuanbo Yang and Gi-Heon Kim
}

The objective of this task is to generate a physics-based, flexible, and efficient simulation methodology to predict electrical-thermal-chemical responses of battery cell/pack subject to sudden mechanical failures such as crush or penetration. In the course of efforts to simulate such a complex event, we introduced a decoupled or a sequential modeling strategy relying on our understanding of the wide disparity in the time scales between mechanical deformation and following thermal and chemical behavior of a battery involved in the event. In this task, NREL researchers developed multi-layer puncture response model to capture the post-impact failure behaviors in the relation with cell form-factors, capacity, and chemistry.

The Multi-Layer Puncture Model captures battery multi-physics responses under mechanical failures. This model works independently, taking short resistances as a character parameter describing actual mechanical failure, or ideally evaluating it from implicit relations using geometry inputs from mechanical crush modeling results. This model is developed based on NREL's safety modeling capability gained over years. Under the given TARDEC project, we have developed new model capabilities critical for simulation of battery behaviors following a mechanical impact such as bullet penetration:

\section{Built a Co-Simulation Environment}

A MATLAB-Fluent co-simulation environment (Figure A) has been established, in which the fluent is a server and MATLAB works as the client. Messages are directly transferred between the two software tools. The MATLAB-based electrochemical and abuse reaction kinetics model are linked with the electro-thermal and heat transfer models in Fluent. This enables the prediction of multi-physics responses of battery units and user to monitor important signals including voltage, current and temperature.

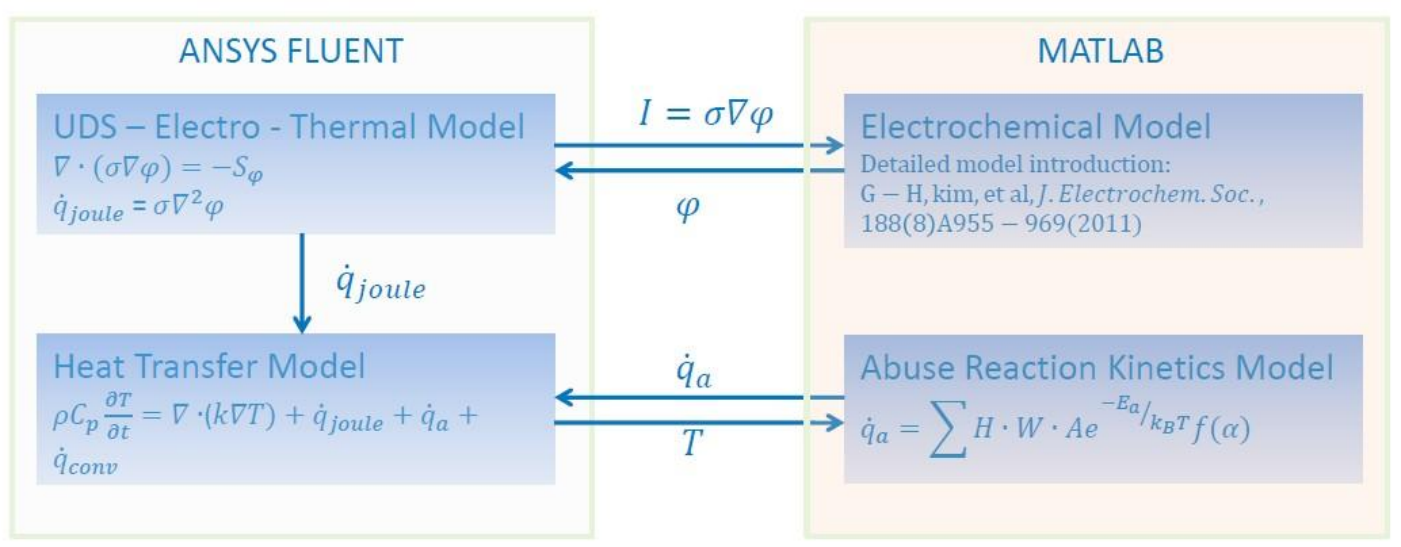

Figure A. A co-simulation environment for multi-layer puncture modeling 


\section{Extended Electro-Thermal Modeling Capabilities}

The electro-thermal model resolves cell or pack electrical behaviors, predicting fault current flow and non-uniform joule heating. The electro-thermal modeling capabilities are significantly enhanced.

- Short resistance as an explicit or implicit parameter

The model previously takes the nature of an induced short nature (electrical resistance) as an explicit input parameter. The current model is also able to implicitly determine electrical resistances according Pouillet's Law. This capability is necessary if mechanical modeling results are directly imported.

- Single layer to multiple layers

The current NREL's internal short circuit model considers a short occurring between a single pair in an electrode sandwich. This restriction has been removed for TARDEC project. The short may occur between multiple pairs of electrode sandwiches, and each shorted layer (or its resistance) is identical.

- Pouch cells to cylindrical and wound prismatic cells

The electro-thermal model is extended for most popular form factors including pouch, cylindrical and wound prismatic cells, as shown in Figure B. Except voltage, current, and temperature, this model in Fluent is capable of visualizing current flow within a cell so as to help users determine the effects of other layers on the shorted layers. This capability extension enables investigating the impacts of cell design and geometrical characteristics.
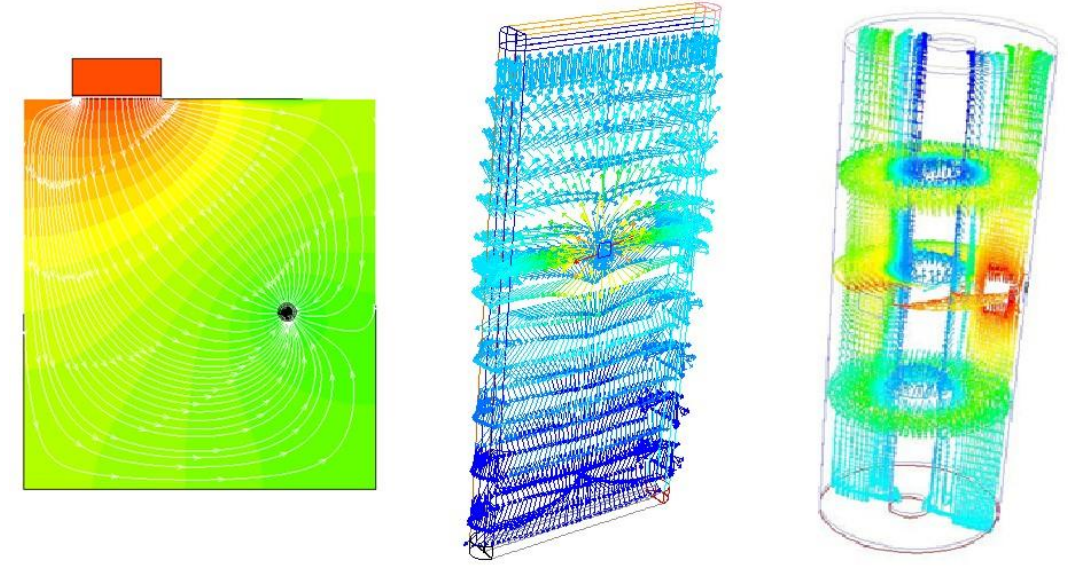

Figure B. Illustration of 3D fault current flow in a pouch cell, a wound prismatic cell and a cylindrical cell respectively subject to mechanical puncture

- 3D electrical behaviors

Instead of using lumped element modeling approaches, the electrical and corresponding joule heats are now calculated in a completely 3D distributed manner. This not only helps accurately determine electrical-thermal behaviors within a cell, but captures electrical characteristic across cells. This is important 
especially for pack simulation because connections (e.g. busbar) and other safety devices play a non-negligible role in abusive events.

3. Performed model validation against small module fault propagation data

The multi-layer puncture modeling approach has been validated with failure propagation studies recently carried out by the Battery Abuse Testing Lab at Sandia National Laboratories. The multi-layer puncture model provides acceptable prediction results (Figure C) of the failure propagation behaviors. A number of observations using the model give insights regarding the failure propagation characteristics.
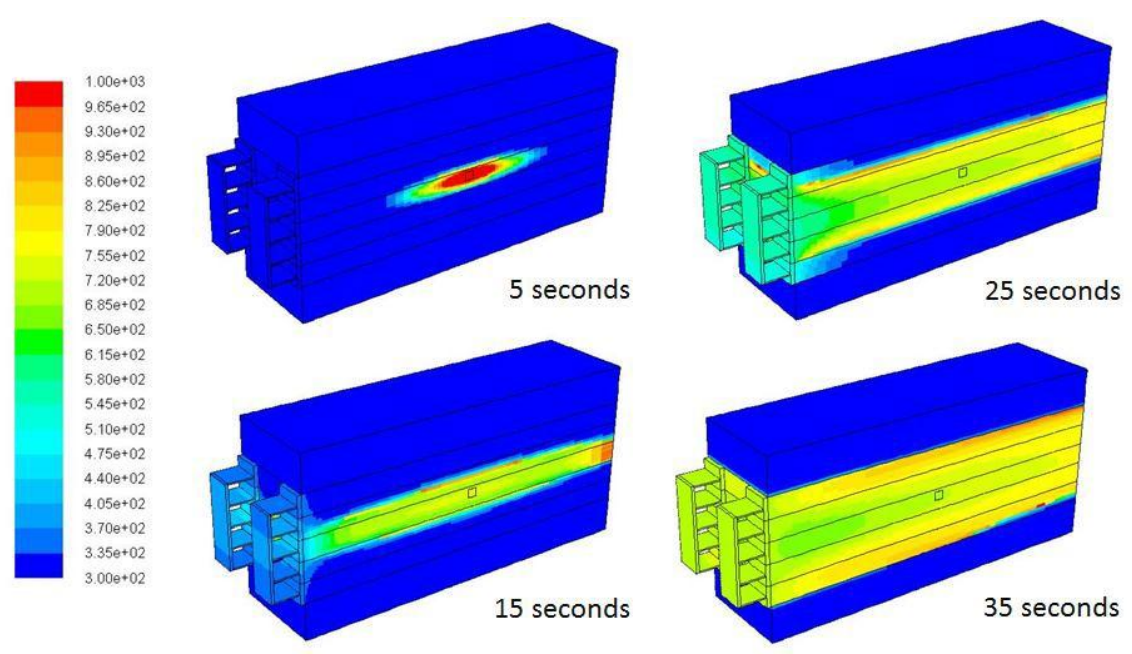

Figure C. Temperature contours of the Sandia National Laboratories' battery module at 5, 15, 25 , and 35 seconds, respectively, after short initialized

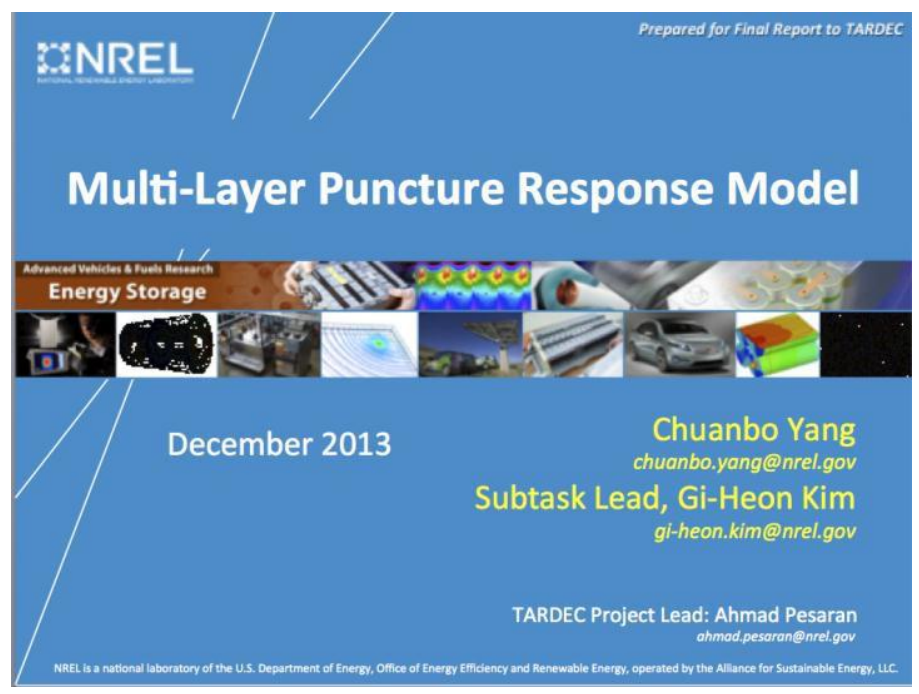

Please click above to link to the presentation 


\title{
1. Safety and Abuse Modeling of Cells \\ b. Bullet threat/strike/penetration \\ ii. Modeling using dynamic structural analysis tools
}

\author{
Prepared by Andreas Vlahinos
}

The main objective of this research effort is to evaluate and select finite element analysis modeling techniques that can effectively simulate bullet penetration into batteries.

The following tasks were completed:

- A parametric solid model of a prismatic battery cell was generated. The number, thickness, and height of the battery cell layers will be parameters of the model.

- A parametric solid model of a bullet was generated. The length, diameter, and conical transition shape will be parameters. This will allow the bullet to be modified to a specified caliber.

- A parametric solid model of the battery and bullet assembly was generated. The bullet height and orientation will be variables of the model. This will allow the bullet position to be modified to a specified line of fire.

- A finite element mesh using the battery and bullet assembly was generated. The elements are solid, and the mesh is appropriate for explicit dynamics simulations.

- A material data set with the appropriate material properties for impact simulations was developed.

- The explicit dynamics software LS_DYNA was used to investigate the failure modes of the battery when penetrated by a bullet. The simulations will predict the impact crater geometry for a specified velocity and caliber bullet.

- Several models for various bullet heights and line of fire orientations, thicknesses, and failure strains of the battery materials were generated and executed.

- Several animations of the bullet penetration were generated to explore the deformed geometry and the strain distributions. Various camera positions such as top, side isometric, and section views were used. The wave propagation was captured.

- For selected cases, the explicit dynamics model transferred the bullet-deformed cell geometry to an electrochemical-thermal finite element model that can predict the electric resistance and transient thermal behavior of the battery.

- A new finite element mesh using the battery and bullet assembly was generated. Shell elements are used that allow delamination of the layers.

- A presentation entitled "Simulation of Bullet Penetration into Batteries" was presented to the TARDEC team. The summary of the modeling techniques was presented and may be found in presentation file linked below. 


\section{Recommendations/Future Activities}

- The deformed shapes of the latest shell model are very similar to the ones observed in the experiments.

- The technical maturity of the simulation process allows us to generate multiple cell and pack models. The NREL team is ready to execute bullet penetration simulations using multiple cell and pack models.

- Mechanical battery material properties for various strain rates and temperatures are necessary for accurate simulations. The NREL team has established a test plan of battery materials, in order to determine the material properties for various strain rates and temperatures.

- As soon as the experimental results are available, the NREL team will evaluate, select, and calibrate temperature-constitutive material models.

- As soon as the electro-thermal material properties results are available, the NREL team will transfer the mechanical bullet-penetrated models to transient electro-thermal models and predict current and temperature versus time and the possibility of thermal runaway.

- Since the models are parametric and linked, the NREL team can perform optimization studies on selected design variables to minimize vulnerability of batteries to bullet penetration.



Please click above to link to the presentation 


\section{Safety and Abuse Modeling of Cells \\ b. Bullet threat/strike/penetration \\ iii. Bullet penetration testing for "validation"}

Prepared by Ahmad Pesaran with input from the Lockheed Martin team in Littleton, CO

In checking the validity of these models, we tried to obtain data on the state of a cell after bullet penetration. Except for an ARL report on bullet strike in lithium-ion pack with cylindrical cells, we could not obtain any public-domain bullet penetration test results for the cells in which TARDEC was interested. So we decided to perform bullet penetration tests under this task to gain more insight for "validation" of the models. To conduct these tests, we subcontracted Lockheed Martin Corporation (LMCO) in Littleton, Colorado, based on their experience with bullet testing on other objects. The bullet penetration tests were conducted near the end of the project, in August and September 2013, on cells provided by TARDEC. The cells we tested included: 1) NCA/graphite chemistry in hard case 25 Ah cylindrical cells from Saft (Model VL 25M); and 2) Iron-phosphate/graphite chemistry in 20 Ah soft pouch prismatic cells from A123 Systems (AMP20mIHD-A). LMCO performed the bullet tests with stringent safety procedures using a 0.308-caliber NATO rifle, model DPMS LR-308, and 0.308-caliber ammunition with full metal jacket ball.
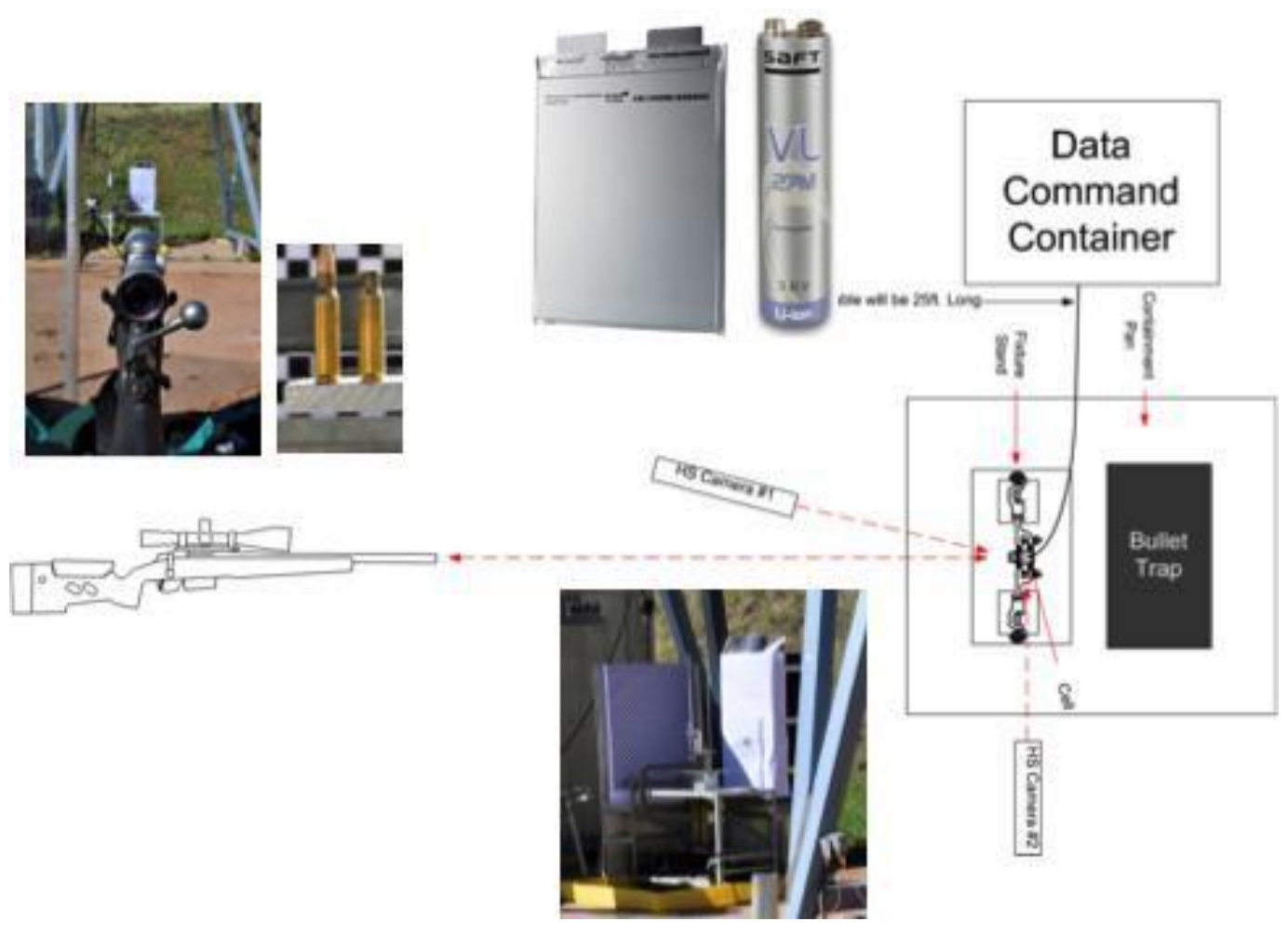

Test set up, cells, rifle, and ammunition for bullet penetration testing 
The bullet strike tests were conducted with Saft cylindrical cells at three states of charge $(0 \%$, $50 \%$, and $100 \%$ ) and two penetration angles $\left(90^{\circ}\right.$ and $\left.60^{\circ}\right)$. We used two A123 prismatic cells sandwiched together with aluminum plates in front, between, and behind, and two sill pads with three states of charge $(0 \%, 50 \%$, and $100 \%)$ and one penetration angle $\left(90^{\circ}\right)$. The cells were instrumented with 10 thermocouples for measuring the temperature of cells at various locations after the bullet strike. We also installed voltage tabs to measure any voltage change after the bullet strike. High-speed cameras (25,000 frames per second) and high-rate data acquisition systems were set up to observe the response of the cells right after the very high-speed event of the bullet strike. We observed very interesting results--some supporting our modeling approach and associated results, and some contradicting our model findings. We did not have enough time to fully analyze the bullet penetration for two sets of tests after damage was incurred by the bullet strikes. We conducted full 3D CT scans of one Saft cylindrical cell and one A123 pouch prismatic cell to better understand what happens to cells after bullet penetration.

For cylindrical NCA Saft cells:

- Bullet penetrated all the way through the cell; the exit point of the cell had much more damage than the entry point

- Cell voltage was lost (went to about zero) immediately after bullet impact; this was due to the electrodes being shorted, as the voltage began to taper to $0.0 \mathrm{~V}$ as the current from the short decreased

- Minimal heating at $0 \% \mathrm{SOC}$, with cell temperature registering at $35^{\circ} \mathrm{C}$; greater heating at $50 \% \mathrm{SOC}$, with cell temperature increasing to $120^{\circ} \mathrm{C}$--electrolyte leaked in these cases, with some smoke, but no fire

- The only cell that experienced fire and flame was the one at $100 \% \mathrm{SOC}$ with a penetration angle of $90^{\circ}$; cell temperature increased to more than $500^{\circ} \mathrm{C}$; the cell at $100 \% \mathrm{SOC}$ hit by a bullet at an angle of $60^{\circ}$ did not catch fire, but electrolyte escaped as smoke or leaked, which could have ignited had there been an ignition source
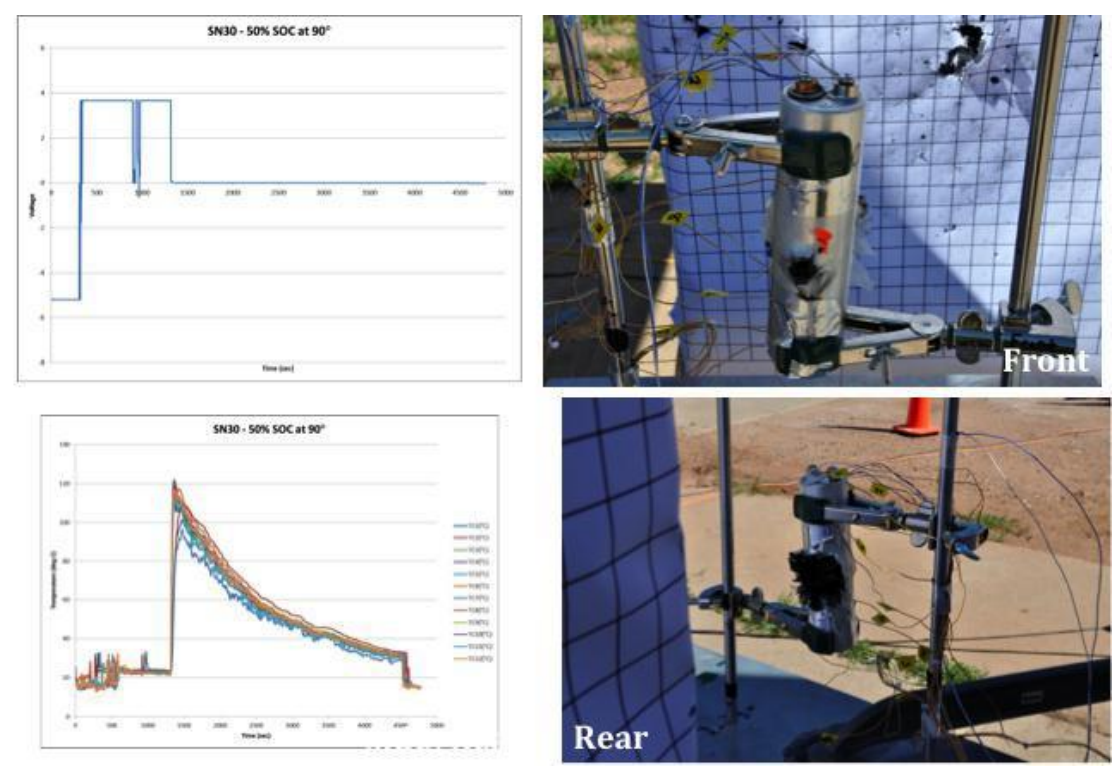

Results from bullet striking the Saft cell at $50 \%$ SOC and $90^{\circ} \mathrm{C}$ penetration angle 
The full 3D CT scan of the cell at $100 \%$ SOC penetrated by a bullet at $90^{\circ}$ showed that the shock wave from the bullet heavily damaged electrodes throughout the entire cell, and was not limited to the bullet penetration site. In addition, the cell header was also severely damaged.
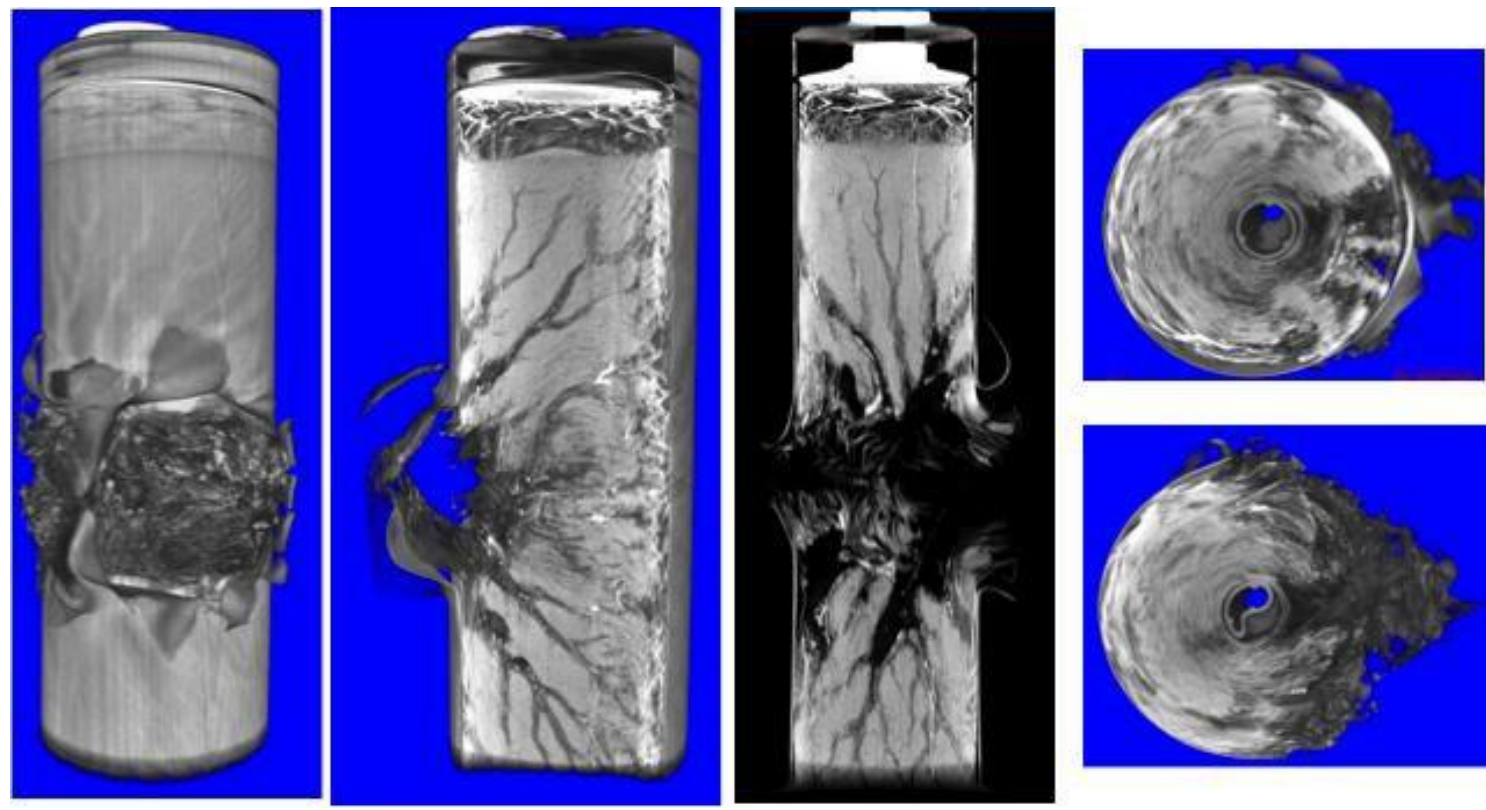

\section{D CT scan of $100 \%$ SOC Saft cell after bullet penetration}

For soft pouch prismatic iron-phosphate A123 cells:

- Generally, the cells saw much less damage than wound cylindrical cells, perhaps due to lack of destructive shock waves

- Generally, more damage was seen in the back cell of the two-cell assembly

- In the three cases we tested, the back cell in the assembly lost voltage immediately due to shorting; we believe this was mostly due to rupture of the middle aluminum plate and sharp metal edges that shorted the back cell

- The front cell did not short in two cases, but with the $50 \%$ SOC case lost voltage 10 minutes after bullet penetration

The bullet penetration tests provided insight on how cells are impacted physically and potential subsequent thermal events depending on situational geometry, chemistry, SOC, and angle of attack. 3D CT scans provided insightful information to further understand what happened to the cells upon bullet impact. The number of tests we performed was limited due to budget constraints and availability of cells, so not too many general conclusions could be made. The tests did provide useful information, though, on improving bullet penetration models.

If funding becomes available, we would like to further study the data and results of bullet penetration tests and further investigate the CT scans. Then we would like to perform a set of 
more comprehensive bullet penetration tests on cells and representative 6T modules. With modeling, bullet penetration tests, and CT scans, we will be able to provide tools to TARDEC to evaluate alternative Li-lon $6 \mathrm{~T}$ battery designs and provide guidance to vendors on improving the design of $6 \mathrm{~T}$ modules with better performance, safety, and life.

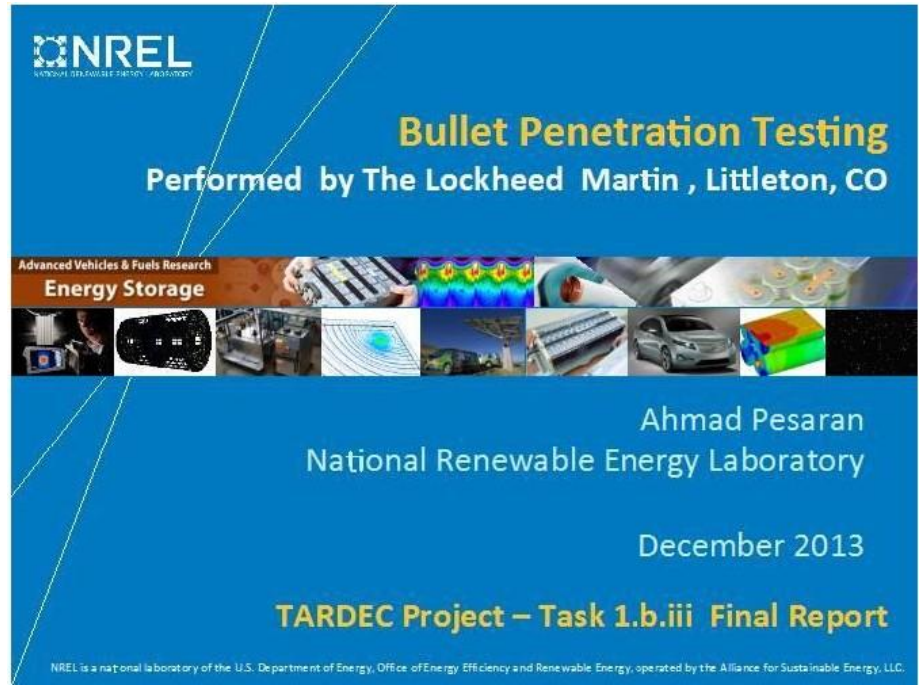

Please click above to link to the presentation 


\section{Multi-scale Electrochemical Modeling with Mechanical Degradation a. Stress in electrodes}

Prepared by Kandler Smith with input from Kurt Maute of University of Colorado at Boulder

Batteries suffer from capacity and power fade due to mechanical, thermal, and electrochemical interactions. To date, the majority of the battery modeling literature has focused on active material particle stress and fracture as being the main contributor to mechanical degradation of Li-ion electrodes. This type of degradation is closely correlated with C-rate. However, our analysis of 13 different aging conditions for a commercial Li-ion cell showed small correlation with C-rate, indicating that particle-level stress only makes a small contribution to performance fade for Li-ion cells operating in normal performance ranges. Much stronger correlations were observed linking performance degradation with bulk state-of-charge swings ( $\triangle \mathrm{SOC}$ ) experienced by the electrodes. These changes in $\triangle \mathrm{SOC}$ are independent of $\mathrm{C}$-rate. Temperature swings $(\Delta \mathrm{T})$ also showed some correlation with performance degradation. These strains are thought be linked to degradation due to (i) dislocation of electrode particles relative to one another creating new sites for SEI growth, and (ii) inducing stress on the polymer separator causing visco-elastic creep and pore closure over many cycles.

Given the importance of bulk $\Delta \mathrm{SOC}$ and $\Delta \mathrm{T}$ changes on electrode and cell expansion and contraction, we worked with the University of Colorado at Boulder (CUB) to link NREL's large format cell-level Multi-Scale Multi-Domain (MSMD) model with a new solid mechanics model developed by CUB under subcontract. To complement the modeling study, NREL performed electrochemical characterization and aging tests on large format 8Ah pouch cells from DowKokam. Dependence of cell expansion and contraction with $\triangle \mathrm{SOC}, \Delta \mathrm{T}$, calendar, and cycling age were measured. The table below shows strain measurements for the DK 8 Ah pouch cell (with nominal thickness $\sim 6.8 \mathrm{~mm}$ ).

Table 1. Measured expansion of unconstrained 8Ah pouch cell

\begin{tabular}{ll} 
Reversible thermal expansion $^{1}$ & $1.1 \mu \mathrm{m} / \mathrm{K}$ \\
\hline Reversible expansion from $0 \%$ to $100 \%$ SOC & $100 \mu \mathrm{m}$ \\
Irreversible expansion due to gas build-up after & $160 \mu \mathrm{m}$ \\
2 years storage & \\
Irreversible expansion under severe cycling ${ }^{2}$ & $12.5 \mu \mathrm{m} /$ cycle $^{2}$
\end{tabular}

1. Average of 21 cells, each measured in three locations at $4^{\circ} \mathrm{C}$ and $30^{\circ} \mathrm{C}$

2. Based on 200 cycles $1 \mathrm{C}$ charge, $2 \mathrm{C}$ discharge

As an initial step towards capturing the reversible effects of mechanical strain on cell performance, NREL and the University of Colorado at Boulder coded and linked a solid mechanics model to explore mechanical phenomena in lithium-ion batteries. Li-ion batteries are composed of a large number of individual thin layers that are stacked together. To correctly 
capture the plate-like behavior of individual layers while limiting the in-plane discretization, a computational mesh with large aspect ratio elements is needed. The chosen solid shell element approach, implemented in MATLAB, accurately captures both in-plane and out-of-plane behavior of individual layers and avoids spurious stiffening effects common with alternate numerical discretization.
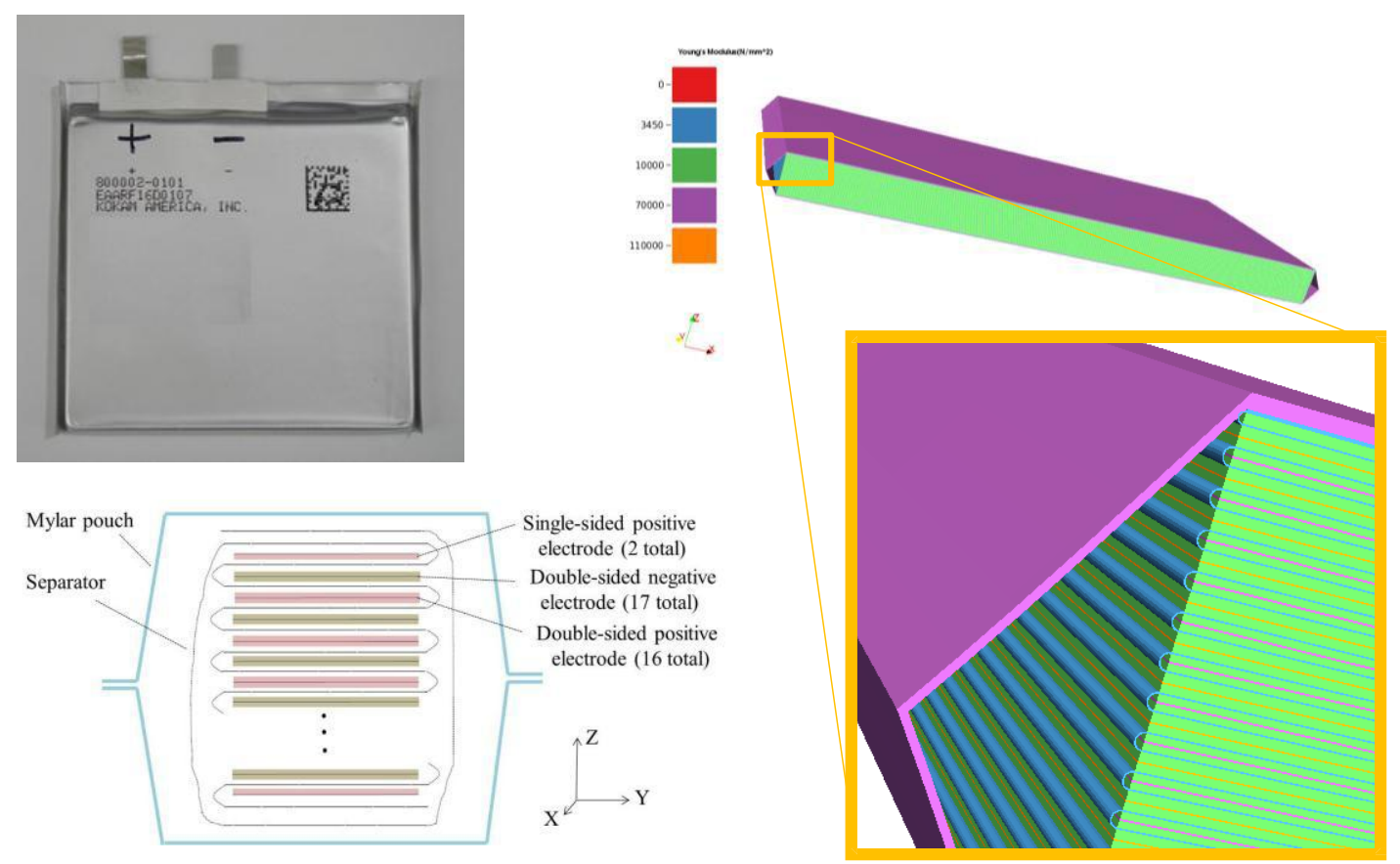

\section{Construction and finite element mesh for 8 Ah pouch cell}

Example simulation results for the 8 Ah pouch cell are given in the final report presentation, linked below. The simulation study showed the largest stresses in the cell occurring at the edge of the electrode stack at the Z-fold separator wind. Under unconstrained mechanical boundary conditions, the in-plane displacement of the cell was found to be larger than in the throughplane direction. The linked 3D electrochemical/mechanical model predicts stress/strain gradients mainly at edge regions, with apparent weak dependence on overpotential gradients near the cell tabs. It is uncertain whether this remains true for other cell designs and dynamic discharge duty cycles. Temperature rise from the electrochemical/thermal model was found to account for a non-negligible portion of the total mechanical strain, with $\triangle \mathrm{SOC}$ capturing the rest.

We feel this model development represents a significant step forward for physics simulation of electrochemical/thermal/mechanical degradation processes in large Li-ion cells. Pending future funding, next steps are to couple stress/strain field variables with cell-level degradation mechanisms known to be an issue for large cells such as:

- Separator creep/pore closure

- Electrode creep/particle displacement 
- Gas generation

- Delamination of layers

Model characterization and validation may be focused on designs and application profiles of interest to TARDEC, and/or making use of existing data as best as practical.

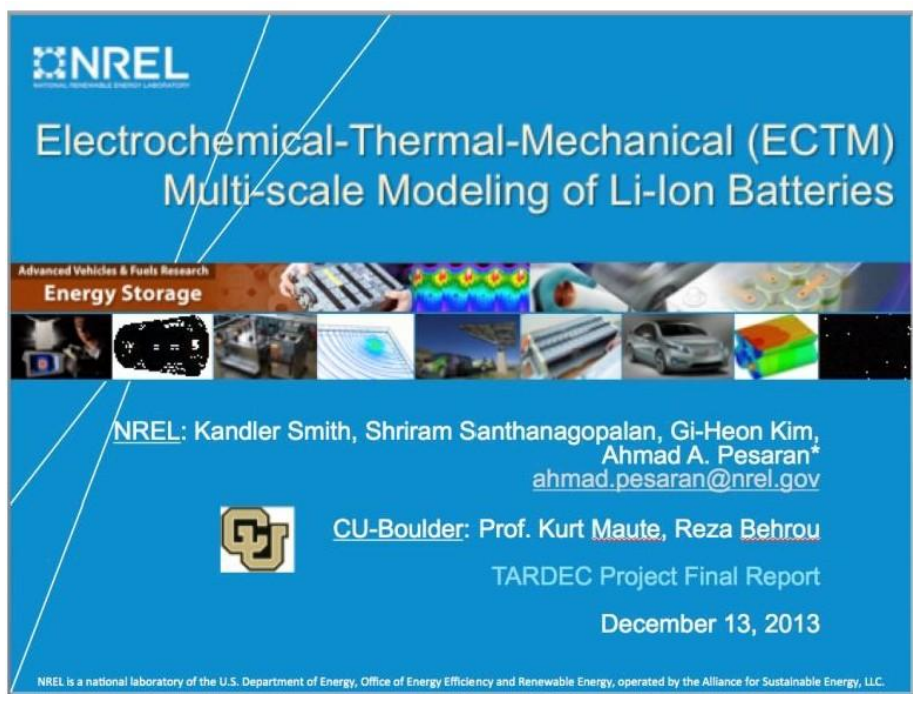

Please click above to link to the presentation 


\section{Interactions with TARDEC End Users}

The NREL project team had several web meetings and one face-to-face discussion with the TARDEC project team to learn about the eventual end use of project modeling tools to modify and adjust them to better meet TARDEC's needs. The NREL team learned about the 6T module, cells, and chemistries that TARDEC was considering for drop-in replacements for lead-acid batteries. To make the models useful, we prepared use instructions to be shared with TARDEC.

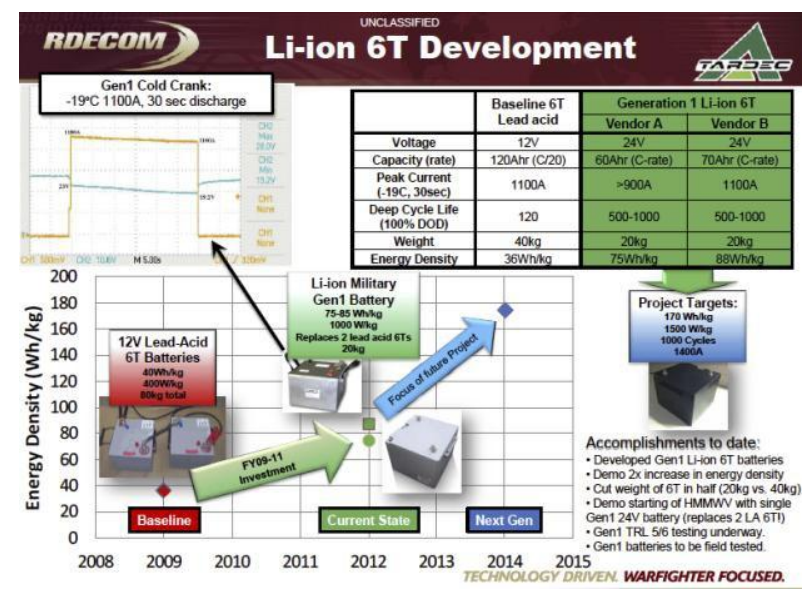

TARDEC vision for Li-Ion 6T development

Based on TARDEC input, we considered hard-can cylindrical cells and soft case pouch prismatic cells. The chemistries considered were iron-phosphate/graphite and nickel-cobaltaluminum/graphite. The models could then be modified to consider different shapes and chemistries with relevant characteristic input. The NREL team had a face-to-face meeting with the TARDEC team in December 2013 to discuss the utility of the models, bullet penetration studies, and next potential steps. The NREL presentation made at the December meeting is linked below.

\section{DNREL}

\section{Final Review Meeting with TARDEC}

Developing Battery Computer Aided Engineering Tools for Military Vehicles

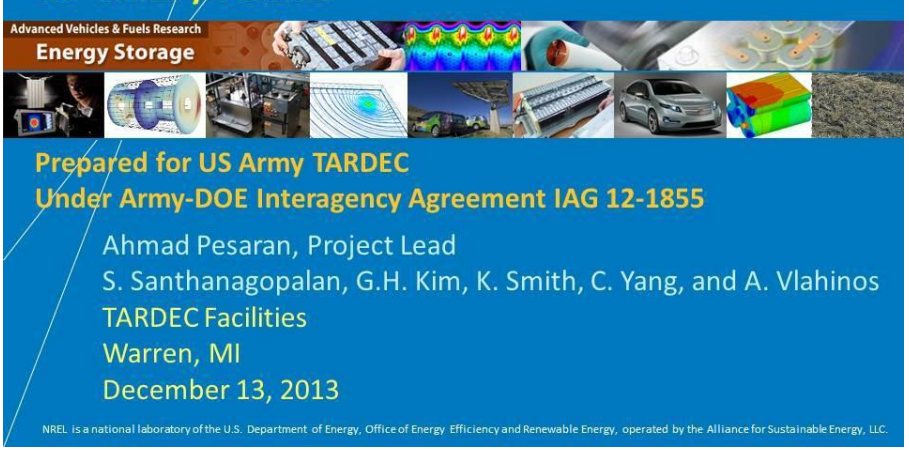

Please click above to link to the presentation 


\section{Proposed Future Work}

Future work includes implementing case studies of immediate interest to TARDEC. One example is the study of the cell response in the $6 \mathrm{~T}$ module to abuse scenarios using the models described above. If TARDEC can provide NREL with a few representative modules, NREL will build relevant simulations and test-plans to respond to queries about which design changes are most relevant to improve the safety of the module under a particular failure mode.

With multi-layer puncture modeling capabilities developed by the funded work, we would suggest identifying characteristics of thermal runaway propagation within battery modules or packs subject to extreme heat and mechanical failure, and complete parametric studies to identify design parameters for controlling catastrophic failure occurrence and propagation. We would extend abuse reaction kinetics modeling with additional chemistry options, while analyzing LS_DYNA simulation results of bullet penetration with refined mesh.

If funding becomes available, we would like to apply it to the further study of data and results of bullet penetration tests and resulting CT scans. Those efforts would help us develop a set of more comprehensive bullet penetration tests on cells and the representative 6T modules in which TARDEC is most interested. More detailed models, tests, and data analysis will provide TARDEC the means to evaluate alternative Li-Ion $6 \mathrm{~T}$ battery designs and provide guidance on improving $6 \mathrm{~T}$ modules. Extending the safety and life models developed under this project, along with CAEBAT performance models, is an important step in achieving the expected TARDEC performance, safety, and life goals for $6 \mathrm{~T}$ batteries.

NREL electrochemical and thermal model development including mechanical stress represents a significant step forward for simulating the physics of electrochemical/thermal/mechanical degradation processes in large Li-ion cells. Future funding will allow subsequent research to couple stress/strain field variables with cell-level degradation mechanisms known to be an issue for large cells, and focus model characterization and validation on designs and application profiles of interest to TARDEC to make use of existing data and maximize impact. 